\title{
Exploring appropriate stones for construction in Koya
}

\author{
T. Kh. Mohammed Ali \\ Geotechnical Engineering Department, Faculty of Engineering, \\ Koya University, Kurdistan, Iraq
}

\begin{abstract}
The reason behind using concrete blocks instead of bricks in Koya is that there is no brick factory close to the city; bringing bricks to the city costs a lot of money. In addition, using bricks in buildings takes a longer time than using concrete blocks. As far as the current use of the concrete blocks, most of the tests that take place in the consultation office in the Faculty of Engineering show that the concrete blocks do not match the standard measurements. The tests include only governmental projects; the matter predicates many problems as time runs. Concrete blocks are also inappropriate for the health of inhabitants.
\end{abstract}

\section{Introduction}

Stones have been used in construction in the area for a long time, since they are considered as local materials that need to be drilled. There are different types of stones such as schist, gneiss, sandstone, granite, gabbro, limestone, marble and slate [1].

It is important to study the different aspects of rocks before using them in construction like the place of each rock types and how each of them can be convenient to be used in construction through examining the engineering features of each type. These features are permeability, appearance, porosity, density, workability, durability, hardness and strength. In fact, each rock has its unique features that require different ways of testing [2]. 


\section{Some engineering features of the rocks}

- $\quad$ Limestone is sedimentary rock like dolomite. It does not have division line in its structure, and its absorption is low. It is smooth and unified in its structure. It is characterized by its high resistance for pressure and tightness. It is used for walls and floors.

- The sand stone is consisted of interconnected silica. It is between very smooth and very hard in orange, red and light brown colors. Its permeability is $30 \%$ of its size.

- $\quad$ The origin of the granite is igneous rock. It is very hard, strong and ridged. The stone colors are red, pink, green, yellow, white and brown. It is used in floors, walls and roofing.

- Marble is transformed and crystallized from limestone. The size of its granules ranges from medium to coarse. Marble is a white stone but it could be found in other colors depending on other minor metals which marble may contain. Marble is used in floor, roofing, decoration and making statues.

- $\quad$ Slate is metamorphic rock which can be divided into pieces in the form of layer. It can be cut into thin or thick sheets called panels. Slate can be found in black, green, red, grey or purple colors. It is used in floors, stairs, roofing and walls.

- Gabbro is a huge volcanic stone. It is characterized by its class structure resulting from different metals layers. It can be used at infrastructure in pavement and road works.

- $\quad$ Schist is a transformed stone. The size of its granules ranges from medium to coarse. Its granules are amorphous in the form of beetle and parallel. Its colors range from sliver white to all the shades of gray color and brown yellow depending on the concentration of the metals it contains.

- $\quad$ Gneiss is a transformed stone. The size of its granules ranges from medium to coarse and its colors are changing. The chemical feature of gneiss is similar to igneous rocks. It is used in construction of building structures [3].

\section{Drilling methods}

Drilling is necessary whenever stones are available. The right ways should be followed such as putting planes, maps, blast, transportation and cutting the stone according to the required size and amount. The traditional way includes drilling holes inside the rocks, putting the explosives inside them, bombing them and then transporting the rocks. The size, depth of the holes and the distance among them is decided by the quantity of the explosives, the size and hardness of the stone. In general, the small close holes produce small stones while big far holes produce big stones.

There are two patterns to make the blast holes. The first one is the parallel pattern which is so common, the second one is staggered pattern which 
characterized by its inability to produce large stones. There is a special equation to calculate the quantity of stones for each hole.

\section{The use of stones in construction}

Stones can be used as partitions, cover of walls, curtain covers, dams or paving the roads. The small colorful pieces of stones can be used in floors. The small piece of low cost stone can be used as the bases of light concrete of normal resistance or in concrete blocks industry that can be used as partitions in construction of any building.

\section{Results and conclusions}

There are very few studies about the types, amount and places of stones in Koya. The geology researches in the Faculty of Engineering have only very few studies about this subject in very limited areas in Koya. This is due to the lack of the equipments and the trained staff for searching process. The department of geography has information about Balaspa chalky stone, which is a crystallized limestone with chips of $150 \mathrm{~mm}$. This stone is produced as a result of its cracks and the activity of crystals process in it. The cost of work can be predicated after certain investigations about the amount, place and the nature of this stone.

\section{Work plan}

- $\quad$ Obtaining geological maps of Koya by a team of geologists and specialists to choose areas remote to residential locations depending on the scheme of reference for the city of Koya.

- $\quad$ Determining the quality and amount of the stones available.

- $\quad$ Conducting the necessary tests to know the engineering properties of each type of stones.

- Determining the appropriate method of exploration which depends on the geological nature of the area.

- Developing an economic feasibility study including the cost of exploration, preparation, cutting and transportation to determine the economic benefits of the work.

- A workforce from trained and skilled workers to produce stones; using boots in construction in private sector to clarify the resulting aesthetic origin and economic feasibility.

\section{References}

[1] Z .Sacco Buildings Construction Baghdad, Second Edition, 1976.

[2] S. B. K. Kaul and S. K. Shama Building Construction First Edition, 1980.

[3] Rock and Mineral Identification for Engineers US Department of Transportation Federal Highway Administration Nov. 1991. 